\title{
IMPACT OF THE LOADING FREQUENCY AND AMPLITUDE ON SELF-HEATING OF ELASTOMERS UNDER LARGE CYCLING DEFORMATIONS
}

\author{
KLiment Hajov, Verjinia AleXandrova* \\ Department of Applied Mechanics, University of Chemical Technology and \\ Metallurgy, 8 Kliment Ohridski Blvd., 1756 Sofia, Bulgaria
}

[Received: 28 June 2019. Accepted: 21 October 2019]

doi: 10.7546/JTAM.49.19.04.06

\begin{abstract}
The aim of this work is to study the influence of the loading frequency and loading amplitude on the self-heating of elastomers at large deformation cycles.
\end{abstract}

KEY WORDS: elastomers, self-heating, cyclic loading, temperature effects.

\section{INTRODUCTION}

Cyclic loading, in some cases, can cause significant heat generation and softening until the material becomes unfit for use $[1,2]$ even when the loading frequency is low enough, the authors of $[3,4]$ study the problem and find the critical temperature of self-heating is strongly dependent on the frequency of the cyclic loading. Based on experimental data, they offer an empirical model to predict critical loading parameters. In [5] the relationship between frequency and temperature, as well as the temperature dependence of the temperature reduction factor, is investigated. The constants of the WLF equation allow determination of the temperature and frequency dependencies of the loss of resistance according to the temperature time analogy. In these studies, the temperature range is limited within $30 \div 150^{\circ} \mathrm{C}$, and excitation frequencies within $1 \div 200 \mathrm{~Hz}$. The authors of [6] examined the influence of the rate of heating on the dynamic mechanical behavior of composite material on a polymeric basis at different excitation frequencies and temperatures. The obtained dependencies allow assessment and determination of self-heating temperature distribution and enhancement under cyclic loading. It is discussed the fact that the results obtained can also be used to determine fatigue, crack growth or residual life of composite structures. In publiclation [7], the vibration of vibroprotective rubber - metal technical articles based on 1,4 cis- polyisoprene rubber is studied. The same authors in $[8,9]$ and [10] on the basis of established temperature and frequency characteristics approximate the function of energy dissipation power, respectively, in elastic and viscoelastic constructions. The authors of [11] analyze the thermomechanical response in the case of cyclic bending of viscoelastic beams made of thermoplastic polymer. The

\footnotetext{
${ }^{*}$ Corresponding author e-mail: aleksandrovassuctm@gmail.com
} 
behavior of the material is modeled taking into account the temperature-frequency dependence of viscoelasticity. Stress, deformation and temperature distributions are expressed in function of beam geometry, loading parameters and material characteristics. In the literature, no data are encountered on the study of the problem in large deformations.

\section{INFLUENCE OF LOADING FREQUENCY}

The study of the influence of loading frequency on the self-heating of the elastomer in these tests established as a temperature enhancement for a specific time (number of cycles) is compared at different loading frequencies.

It proceeds from the differential equation of self-heating [12,13], which is solved in the range of $0.3 \div 5 \mathrm{rad} / \mathrm{s}$ and in the case of imposed strain

$$
\rho C_{p} \dot{T}=\left[\sigma^{v}-d(t) \sigma^{e}\right] \dot{\mathcal{E}}_{\mathrm{imp}}(t)-\frac{h}{H}\left(T-T_{0}\right), \quad\left[\mathrm{W} / \mathrm{m}^{3}\right],
$$

where $\mathcal{E}_{\text {imp }}(t)=\mathcal{E}_{0} \sin (w t)$ is the imposed loading law, $\sigma^{v}$ and $\sigma^{e}$ are viscous and elastic parts of the stress response, respectively, that can easily be derived from the elastoviscous stress response, $\rho$ - density, $C_{p}$ - heat capacity, $H$ - Heaviside function, $h$ - coefficient of heat transfer, $T$ - temperature in the volume of material, $T_{0}-$ initial temperature and $d(t)$ - damage increase in time.

The following figures illustrate the damage enhancement, the imposed strains laws, the stress responses as well as the temperature enhancement for 4 different frequencies of imposed sinusoidal strain laws with respect to the frequency for butadiene nitrile rubber with $70 \%$ carbon black filling. For this purpose, the amplitude of the deformation for all four cases is kept constant and equal to 0.32 .

Figure 1 shows the damage increase in time for four different strain-loading frequencies.

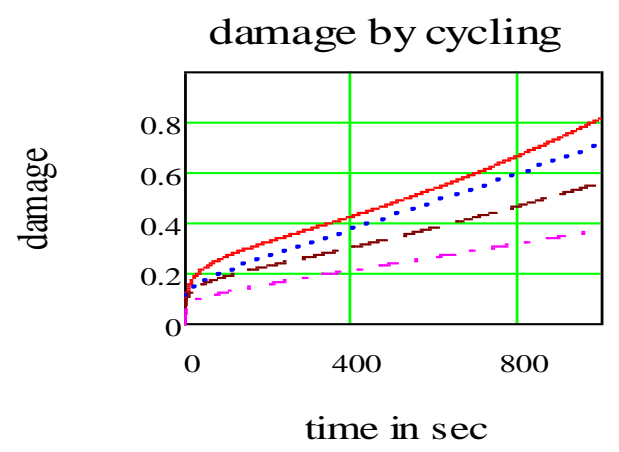

Fig. 1. Damage enhancement for 4 loading strain frequencies: $0.3 ; 0.5 ; 2.0 ; 5.0$ [rad/s]. 
In Fig. 2 and Fig. 3 the imposed strain laws and the respective stress responses for these 4 different loading frequencies are illustrated.
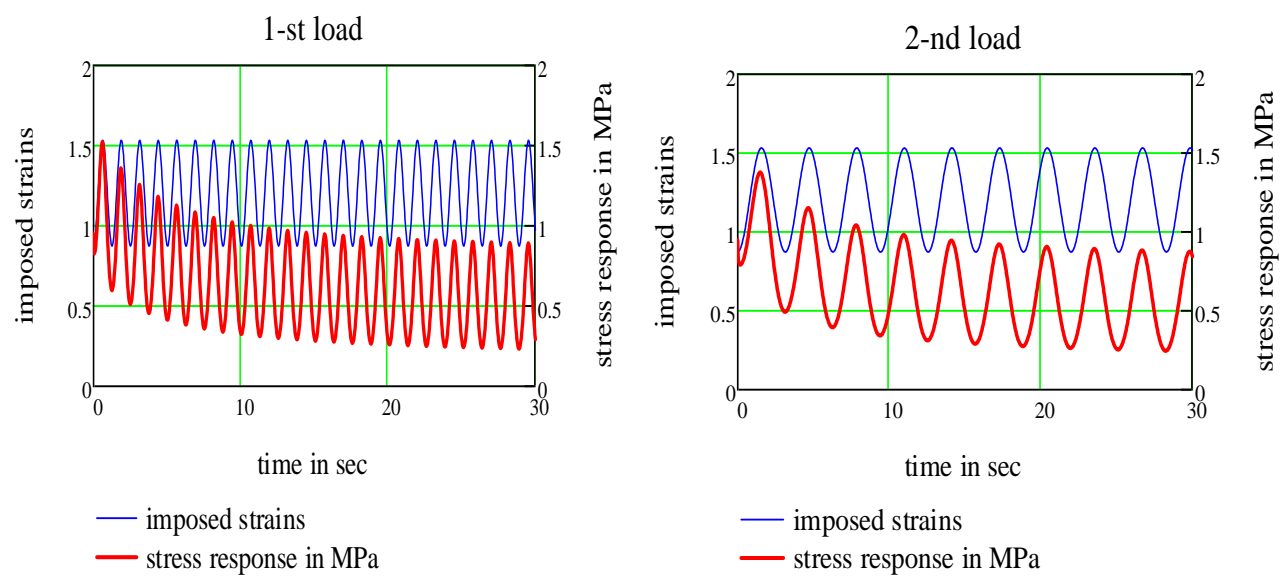

Fig. 2. The first two imposed strain laws $(0.3$ and $0.5[\mathrm{rad} / \mathrm{s}])$ and the respective stress responses [MPa].
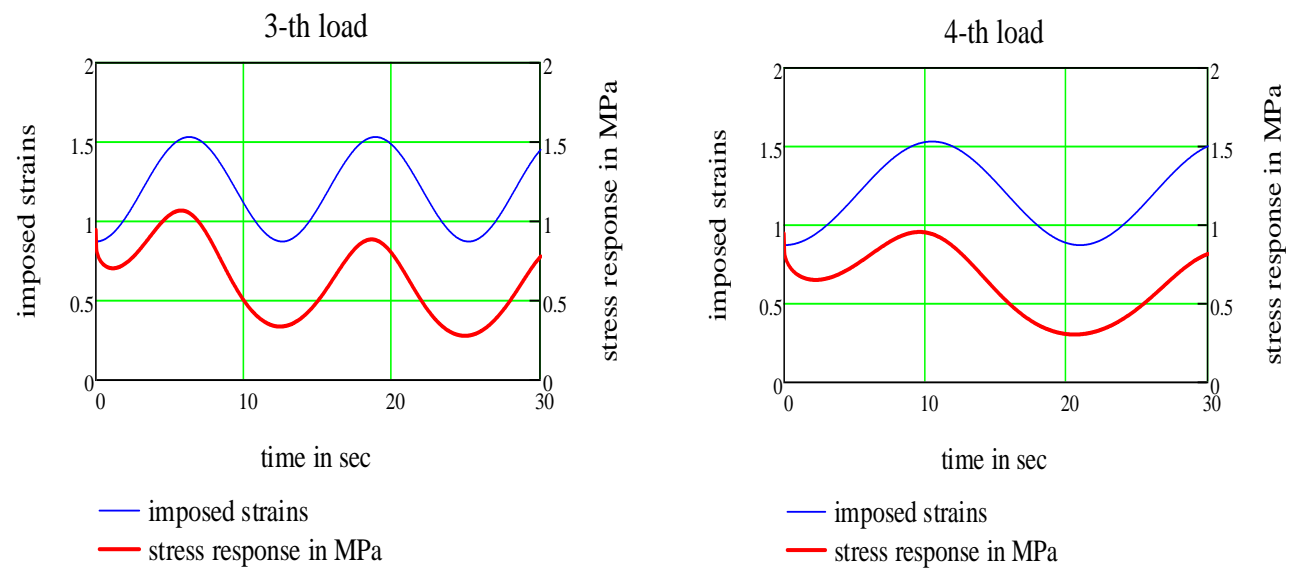

Fig. 3. The second two imposed strain laws ( 2 and $5[\mathrm{rad} / \mathrm{s}])$ and the respective stress responses [MPa].

Figure 4 clearly shows the purpose of the study, namely to compare the results for different loading frequencies at the same amplitude of the imposed strain. It can be seen that the frequency plays a significant role in increasing the temperature during self-heating. As the incidence of strain increases, the temperature of self-heating increases. 


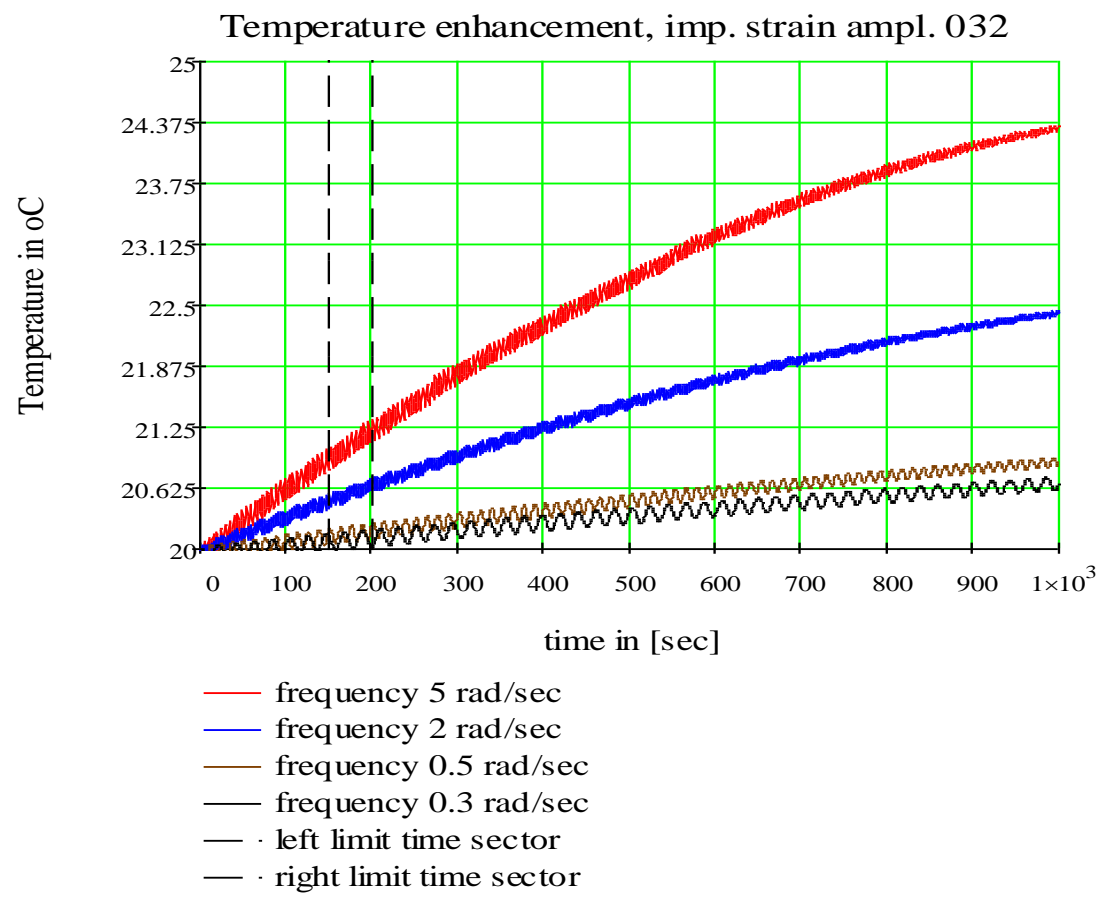

Fig. 4. Temperature enhancement by self-heating for the 4 different cases described above.

Figure 5 shows more precisely the temperature enhancement in the boundaries noted in the upper graph, with the left and right time sectors expanding over time.

The following Fig. 6 shows the influence of the loading strain frequency on the temperature enhancement during self-heating. The angular frequency in radians per second is applied to the abscissa. This is done by calculating the temperature increase for different frequencies (for us from 0.25 to $5[\mathrm{rad} / \mathrm{s}]$ for a specific time (in our case for $500 \mathrm{~s}$ and $1000 \mathrm{~s}$ ) of equation (2).

$$
\dot{T}(t)+\frac{h}{H \rho C_{p}} T(t)=\frac{1-d(t)}{\rho C_{p}} \sigma \dot{\mathcal{E}}+\frac{h}{H \rho C_{p}} T_{0} .
$$

Similar results are also shown in Fig. 7 for butadiene nitrile vulcanization with $70 \%$ carbon black filling. Here the frequency range is slightly larger, but the fixed time is significantly shorter. This is the reason for the lower temperature rise. The influence of the damage is also shown, which is not to be neglected in case of large deformations. As can be seen from the graph, the increase in temperature is more pronounced when neglecting the energy spend to damage. Ignoring the energy spend to damage in large deformations, we redirect it to heat energy increasing the temperature. 


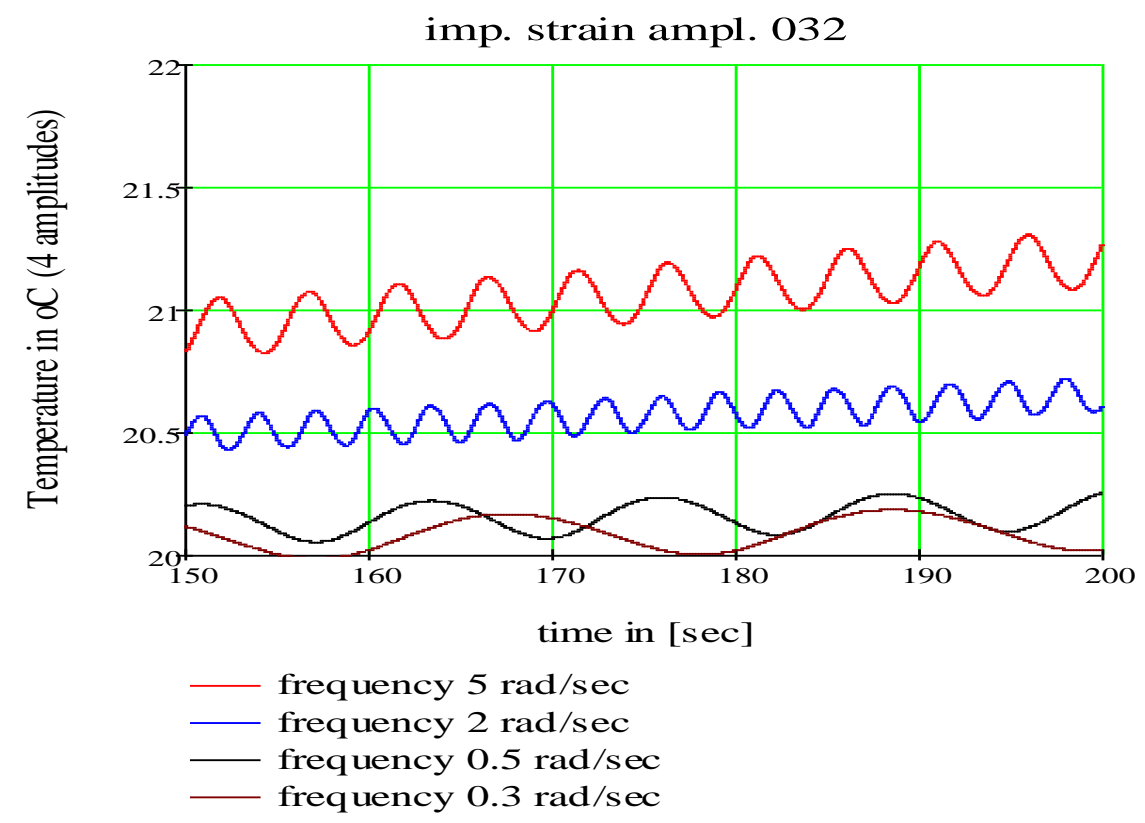

Fig. 5. Temperature enhancement by self-heating related with Fig. 4. The time interval between the vertical dashed lines from Fig. 4 is enlarged here.

Temperature enhancement, strain ampl. 0.32

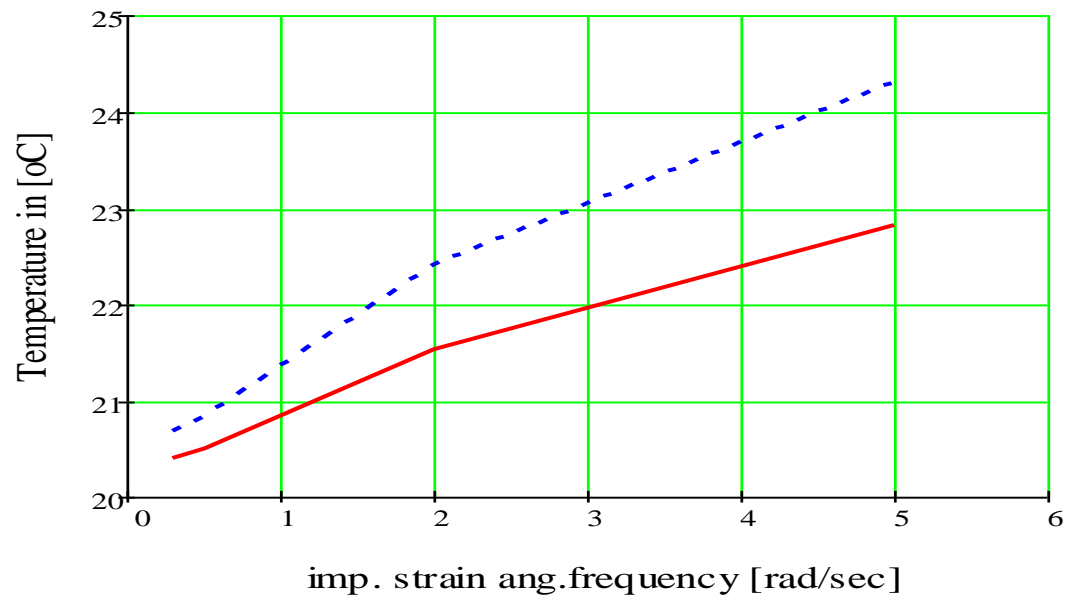

Fig. 6. Temperature enhancement via loading strain amplitude for two fixed times $500 \mathrm{~s}-$ red line and $1000 \mathrm{~s}-$ dashed blue line. 


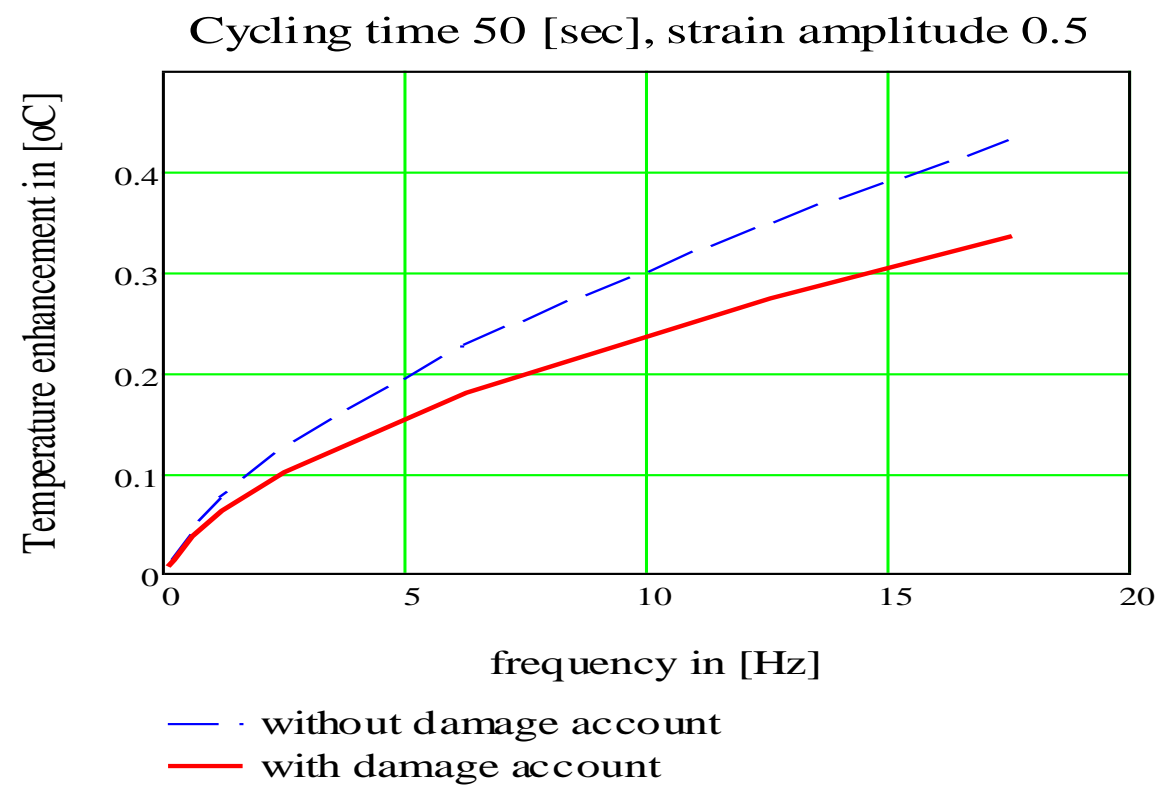

Fig. 7. Temperature enhancement under cyclic loading of $\mathrm{BN}+70 \% \mathrm{CB}$ via circular frequency.

Therefore, in practice, the damage detection involves a decrease of temperature rise in case of self-heating.

\section{INFLUENCE OF LOADING AMPLITUdE}

The authors of $[14,15]$ in cyclic loading experiments with a growing amplitude of stresses observe the development of the so called Mullins softening effect. In $[16,17]$ this effect is recorded in both pure and filled rubber. Losses due to hysteresis are quantitative features of softening.

The dependence of the latter on the amplitude of the imposed strain (stress) has been studied in the works [18-22].

In [23] an analytical relationship between the strain amplitude and the Fourier coefficient is given, and it is noted that in the case of the imposed stress amplitude the results are analogous. A damping function related to damage was introduced in [24] to connect the damping parameter to amplitude damage in order to give it physical sense and show the experience to identify.

In $[25,26]$ the experimental comparisons show that the increase in the deformation amplitude leads to an increase in the loss (dissipation). 
First load

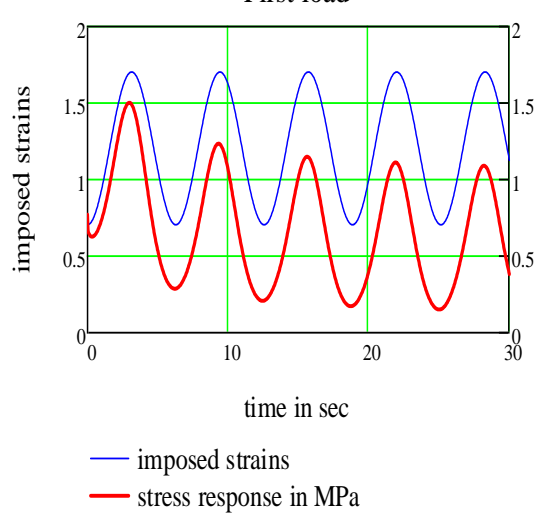

Second load

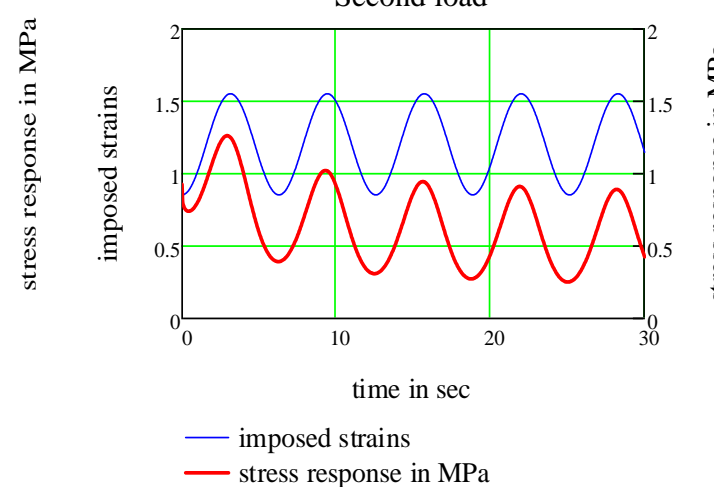

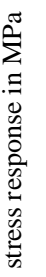

Fig. 8. The first two imposed strain laws ( 0.1 and 0.25 strain amplitudes) and the respective stress responses $[\mathrm{MPa}]$.
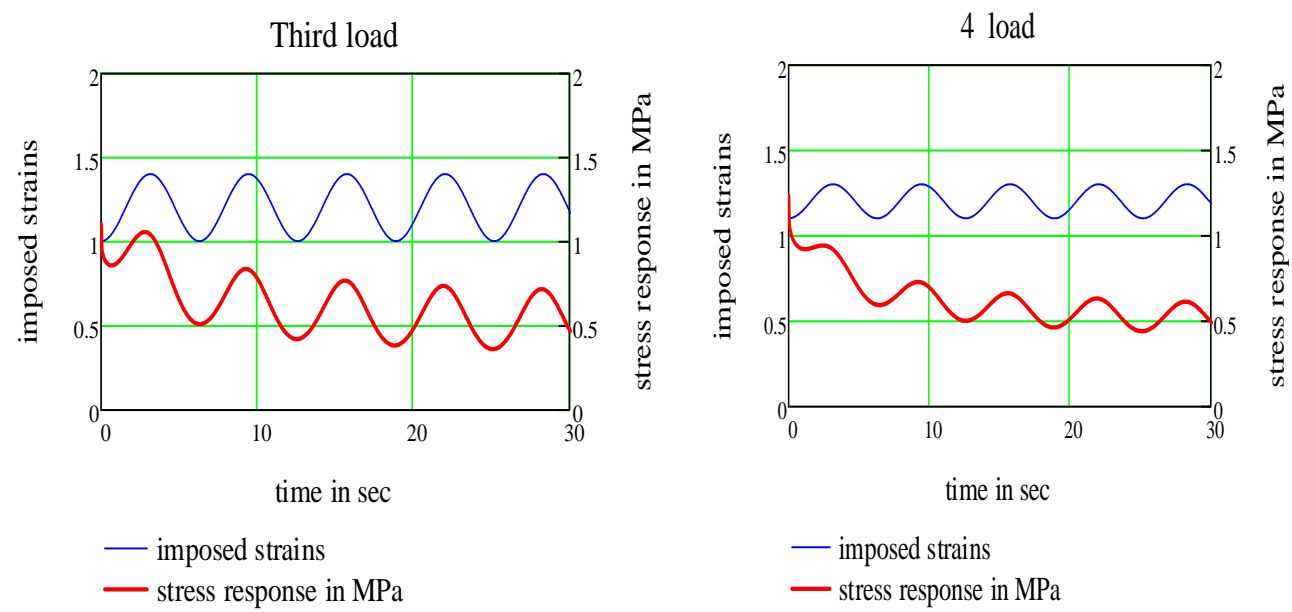

Fig. 9. The second two imposed strain laws (0.35 and 0.5 strain amplitudes) and the respective stress responses [MPa].

Analogous to the first part, Fig. 8 and Fig. 9 show the deformation loading and the stress responses at constant frequency $1 \mathrm{rad} / \mathrm{s}$ for 4 different amplitudes.

Figure 10 compares the temperature enhancement with 4 different strain amplitudes at the same angular frequency.

The figure shows that as the amplitude increases, self-heating increases. 
Temperature enhancement, ang. freq. $1 \mathrm{rad} / \mathrm{sec}$

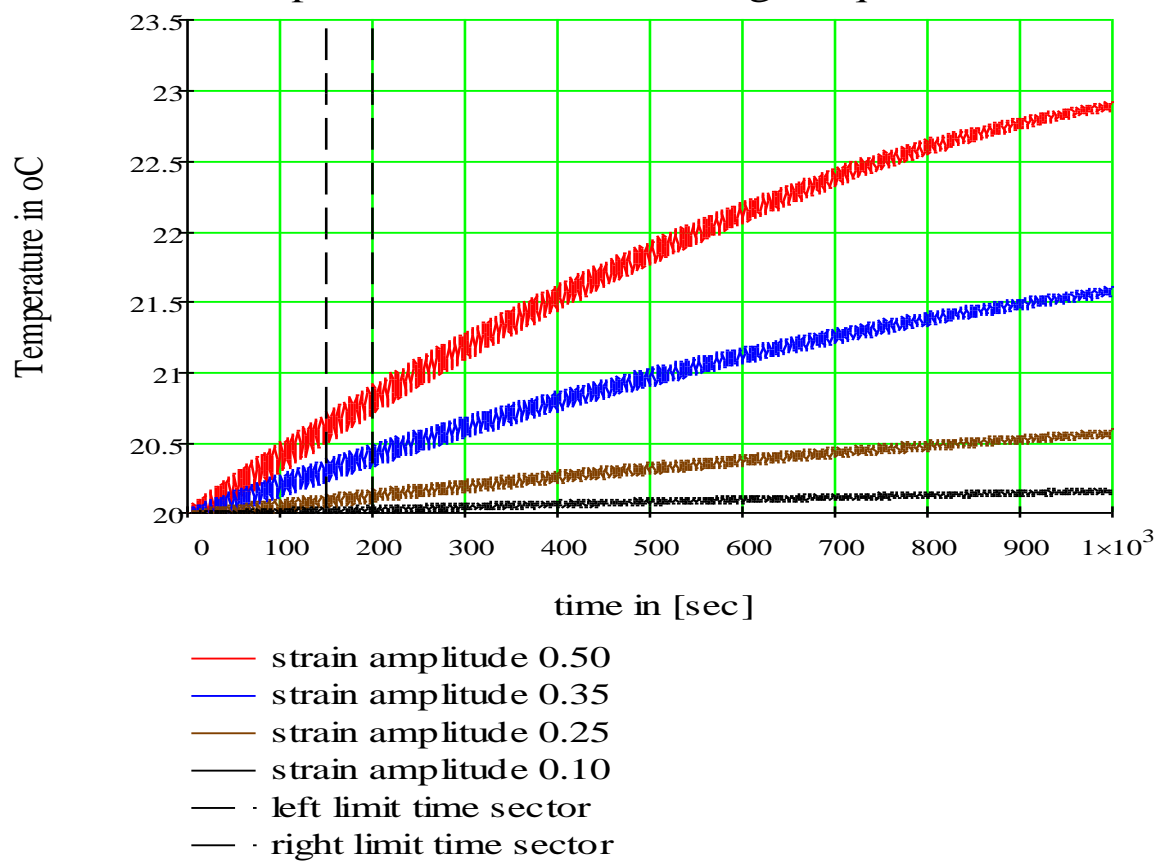

Fig. 10. Temperature enhancement for 4 different strain amplitudes.

Figure 11 shows the theoretical curve and points with experimental results for BN $+70 \%$.

As it can be seen from the figure, the correlation between the theoretical model and experimental data is satisfactory.

Figure 12 shows more precisely the temperature enhancement, between the boundaries noted in the upper graph (Fig. 11 - left and right time sectors expanding over time).

Figure 13 illustrates the increase in temperature as a function of strain loading amplitude. This is done conforming to the solution of equation:

$$
\frac{d}{d t} T(t)=\frac{1-d(t)}{\rho C_{p}} \sigma \dot{\mathcal{E}}-\frac{h}{H \rho C_{p}}\left(T-T_{0}\right)
$$

for fixed time (in our case for $500 \mathrm{~s}$ and $1000 \mathrm{~s}$ ) and frequency (in our case $1 \mathrm{rad} / \mathrm{s}$ ) varying the loading amplitude (in our case from $0.1 \div 0.5$ ). 
Temperature enhancement, ang. freq. $1 \mathrm{rad} / \mathrm{sec}$

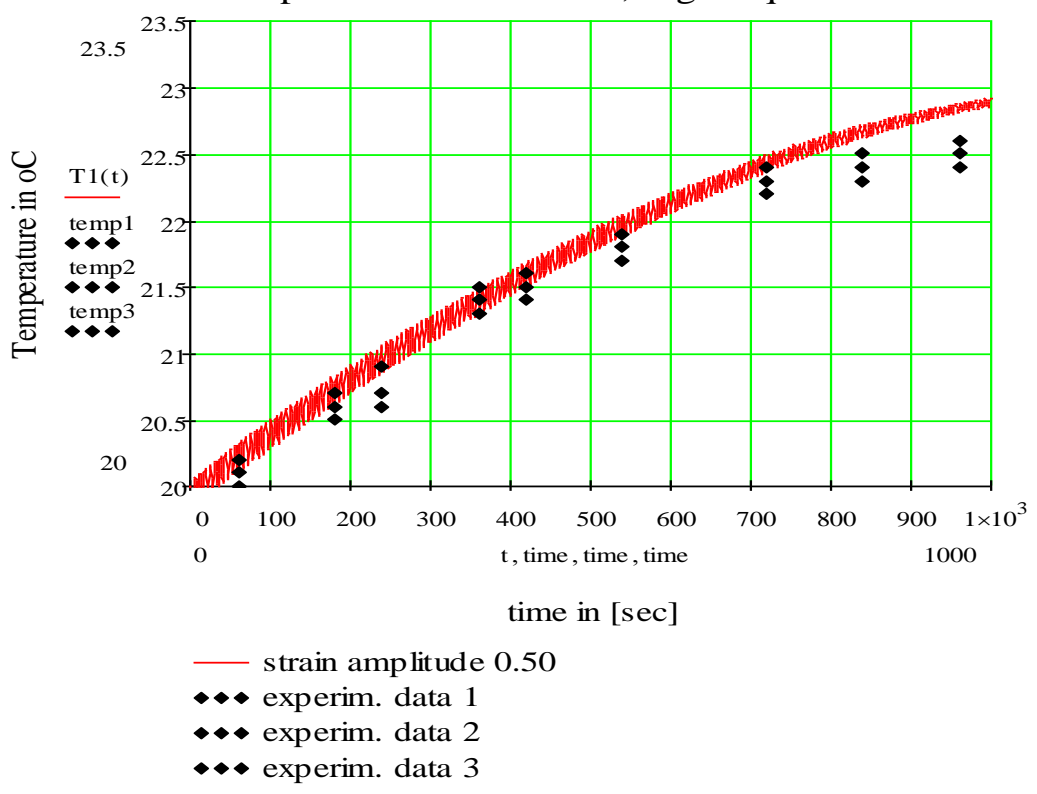

Fig. 11. BN+70\%. Temperature enhancement under imposed strain amplitude 0.5.

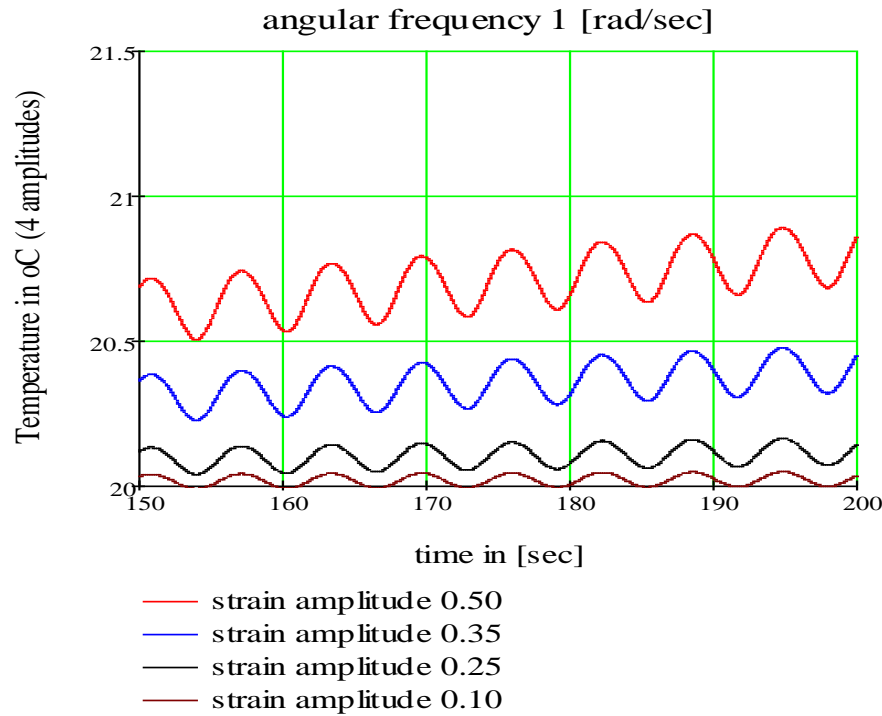

Fig. 12. Temperature enhancement by self-heating under 4 different strain amplitudes related with Fig. 10. 


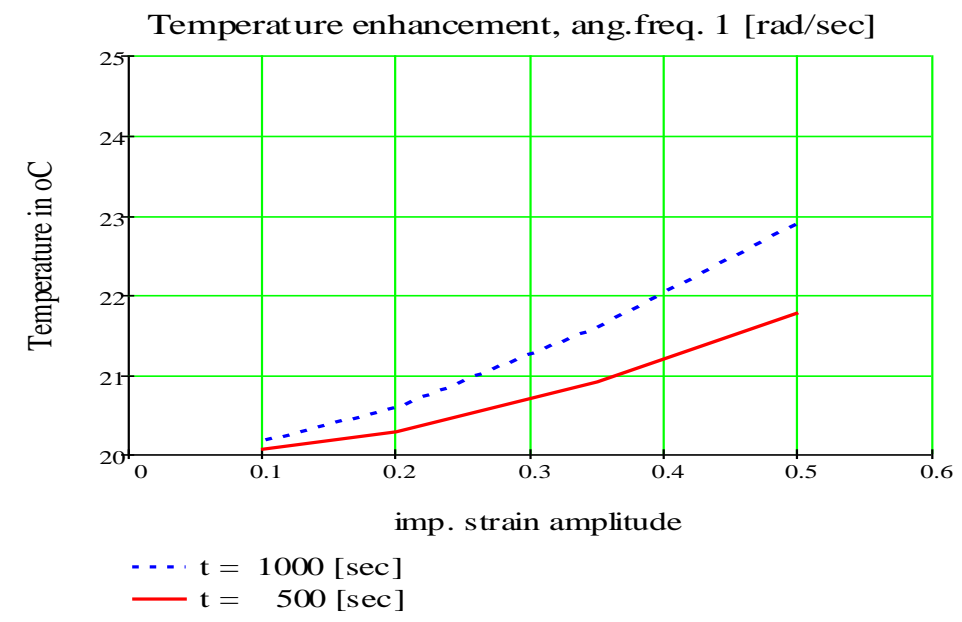

Fig. 13. Temperature enhancement via loading strain amplitude for two fixed times.

\section{CONCLUSION}

Here the following conclusion could be drawn: by comparing the results of Figures 6 and 13 expressing the temperature enhancement under cycling loading in function of the frequency and the amplitude respectively, it is clear that the influence of the amplitude is more pronounced than the frequency. It can be seen that the curve in the second case (depending on the amplitude) increases exponentially and has no tendency to "soothe" as with an increasing circular frequency.

\section{ACKNOWLEDGEMENTS}

The work is financially supported by the NATIONAL SCIENTIFIC PROGRAM "YOUNG SCIENTISTS AND POST DOC", Ministry of Education and Science, Bulgaria.

\section{REFERENCES}

[1] D. Rittel, N. Eliash, J.L. Halary (2003) Hysteretic heating of modified poly (methylmethacrylate). Polymer 44(9) 2817-2822.

[2] J. Ohno, J. Gotoh, M. OKada, M. Takashi, S. Miwa (1997) A temperature rise by heat genaration on viscoelastic body under periodic load. Transaction of JSME Ser. A, 63(610) 1260-1265.

[3] A. Katunin, M. Fidali (2011) Experimental identification of nonstationary selfheating characteristics of laminated composite plates under resonant vibration. Kompozyty 11 214-219. 
[4] A. KATUnin, M. Fidali (2012) Self-heating of polymeric laminated composite plates under the resonant vibrations: theoretical and experimental study. Polymer Composites 33 138-146.

[5] A. Katunin, A. Gnatows Ki (2012) Influence of heating rate on evolution of dynamic properties of polymeric laminates. Plastics Rubber and Composites 41(6) 233-239.

[6] A. Katunin, W. Hufenbach, P. Kostka, K. HoleczeK (2010) Frequency dependence of the self-heating effect in polymer-based composites. Journal of Achievements in Materials and Manufacturing Engineering 41(1-2) 9-15.

[7] A. Aleksandrov, D. Donchev, Ts. Tsolov (2003) Thermal effects in rubbermetal products. Mechanics of Machines 48 23-26. ISSN 0861-9727

[8] A. Aleksandrov, D. Donchev, Ts. Tsolov (2003) Heat formation under viscoelastic deformation of rubber-metal technical products. In: Proceedings of 10th, International Conference on Mechanics and Technology of Composite Materials, September 15-17, Sofia, Bulgaria, pp 237-240.

[9] A. Alexandrov, K. Hadjov, M. Kolev, M. Milenova (2013) Heat formation under cyclic viscoelastic deformation of rubber-metal technical products. In: Proceedings of the Anniversary Scientific Conference with International Participation "60 Years UCTM" 11-14.

[10] M. Kolev (2014) "Predicting of the Mechanical Behavior of Elastomers in Liquid Medium and under Cycle Loading". Dissertation, UCTM.

[11] F. Dinzart, A. Molinari, R. Herbach (2008) Thermomechanical response of a viscoelastic beam under cyclic bending; self-heating and thermal failure. Archives of Mechanics Warszawa 60(1) 59-85.

[12] J. SALENÇON (1995) "Mécanique du Continu” 1, 2, 3 Ellipses, Lemaitre.

[13] K. HAdjov, V. AleKsandrova (under press) Heat generation in rubbers by cyclic loading.

[14] L. Mullins (1969) Softening of rubber by deformation. Rubber Chemistry and Technology 42 339-362.

[15] M. Loo, A. Andriyana, E. Verron, G. Chagnon, A. Afifi (2012) Mullins effect in swollen rubber under cyclic loading. International Journal of Research in Engineering and Technology (IJRET) 1(4).

[16] C. Gauthier, E. Reynaud, R. Vassoille, L. Ladouce-Stelandre (2004) Analysis of the non-linear viscoelastic behaviour of silica filled styrene butadiene rubber. Polymer 45(8) 2761-2771.

[17] B. Meissner, L. MATEJKA (2006) A structure-based constitutive equation for fillerreinforced rubber-like networks and for the description of the Mullins effect. Polymer 47(23) 7997-8012.

[18] J. BAUMAN (2008) "Fatigue, stress, and strain of rubber components". ISBN 978-3446-41681-9, Carl Hanser Verlag, Munich.

[19] D. Wollscheid (2014) "Predeformation and frequency dependence of fillerreinforced rubber under vibration”. Dissertation, Universitt der Bundeswehr München, Fakultät für Luft- und Raumfahrttechnik, Institut für Mechanik. 
[20] G. Huber, T.A. Vilgis, G. Heinrich (1996) Universal properties in the dynamical deformation of filled rubbers. Journal of Physics: Condensed Matter 8(29) L409-L412.

[21] T. Vilgis, G. Heinrich, M. KlüPPEl (2009) "Reinforcement of Polymer NanoComposites". Cambridge University Press.

[22] P. MiIdla (2012) "Book Numerical Modelling": Chapter 15: Radim Halama, Josef Sedlák, Michal Šofer, "Phenomenological Modelling of Cyclic Plasticity". ISBN 978953-51-0219-9, Publisher InTech.

[23] K. Hadjov, V. AleKsandrova (2017) Cyclic loading of rubbers - amplitude spectrum and Payne effect. Journal of Chemical Technology and Metallurgy 52 (2) 415-420.

[24] K. Hadjov, D. Donchev, T. Hrima, V. AleKs androva (2016) Stress and strain controlled cyclic loading. Science, Engineering and Education 1(1) 21-26.

[25] K. Hadjov, D. Donchev, T. Hrima, V. Aleksandrova (2015) Modules complexes des solides viscoélastiques partir des functions fluage et des noyaux respectifs. Presented at FSTS, IIIémes Journées Internationales Matériaux et Environnement.

[26] K. Hadjov, T. Hrima, V. Aleksandrova, J. Javorova, A. Aleksandrov (2016) Loss factor of rubbers as a function of strain amplitude and frequency. Journal of the Balkan Tribological Association. 22(4-II) 4198-4204. 